\title{
The Encroachment of Value Pragmatism on Pluralism: The Practice of the Valuation of Urban Green Space Using Stated-preference Approaches
}

\author{
ALEX Y. LO
}

\begin{abstract}
Monetary valuation of urban green space using stated-preference approaches has gained prominence among pragmatic urban researchers, but the resultant reduced potential for value pluralism has gone unnoticed. There is confusion on value concepts. Public-social values have been treated as private-economic ones. The potential for reflecting the multiple values and social roles of urban nature is thus reduced. Being method-driven, the practice fails to relate to the claimed objective of comprehensively portraying it. There is inadequate understanding of the philosophy and psychology of the values associated with urban green space, despite its multi-faceted role being widely recognized. This results in an unreflective acceptance of economic techniques. More work is needed to clarify issues concerning the manifestation and theoretical foundation of value pluralism. Deliberative approaches may be a potential complementary or alternative valuation method.
\end{abstract}

\section{Introduction}

Urban green space (UGS) consists of natural elements and artefacts. It is defined as the open space situated within city limits with a vegetation cover planted deliberately or left over from pre-urbanization vegetation by design or default (Jim and Chen, 2006). UGS yields a wide range of benefits. Since most of these benefits are non-marketed, although urban land fetches a financial premium, researchers are tempted to translate them into monetary terms. This may be regarded as consistent with the trend for pragmatism in environmental policy, although it conflicts with value pluralism (Spash, 2009). There is tension between the required economic framing and the pluralistic tradition of UGS research.

Stated-preference techniques are non-market valuation techniques developed by economists. They are used to elicit people's preferences through direct inquiry, usually based on a questionnaire survey. The contingent valuation method $(\mathrm{CVM})^{1}$ is the most

The author is indebted to Clive Spash for offering constructive comments on an earlier draft of this article.

1 The stated-preference approach includes CVM and choice modelling. Many of the earlier critiques were directed to the former. The arguments in this article apply to stated-preference techniques in general, although I explicitly focus on CVM. 
commonly used technique. In CVM, an institutional context is created in which a hypothetical environmental change takes place. Respondents are asked to indicate the maximum amount of money they are willing to pay to prevent an environmental change (WTP), or the minimum amount they would accept as compensation for accepting it (WTA). The stated WTP or WTA is taken as relating to the value of the underlying environmental services or goods and used in cost-benefit analysis (CBA) upon aggregation. Although WTA is assumed to be theoretically equivalent to WTP, most valuation studies adopted a WTP approach.

In economics, individual welfare is seen as the building block of social well-being. Stated-preference techniques aim to reveal an individual's consumer preference in the form of WTP and accordingly to produce aggregate monetary estimates to represent the benefits accrued to the society. The WTP is conceptualized as an economic construct under a preference utilitarian model. Individuals are assumed to express their preferences for maximizing personal utility. Many neoclassical economists find the inclusion of human motivations arising out of social altruism and rights-based values particularly problematic for their approach to economic values as measured and used in formal CBA (Spash, 2006).

Value pluralism refers to the view that people care about things on the basis of multiple evaluative attitudes and standards (Anderson, 1993). Pluralist theorists admit alternative motivational bases for human behaviours and doubt the exclusive scope of neoclassical economics. Research has challenged the view that humans act as rational utility-maximizing agents in making choices about public goods, that preferences are linear, invariant and pre-existing, and that value formation is an isolated, asocial process (Sagoff, 1988; O’Neill, 2007; Spash, 2008a; 2008b). The pluralists doubt the potential of CVM to capture non-economic values. It is considered misleading to restrict environmental valuation to hedonic calculus and assume that summing individual preferences amounts to aggregate social well-being. The act of attaching a dollar value to nature is more a social and political choice than a purely economic one. Stated-preference techniques are flawed inasmuch as they take nature as a commodity for pricing.

The pragmatic need for economic estimates nevertheless proves to be overwhelming. Stated-preference surveys have gained prominence among UGS researchers (Tyrväinen and Väänänen, 1998; Tyrväinen, 2001; Kwak et al., 2003; Pepper et al., 2005; Jim and Chen, 2006; del Saz-Salazar and García Menéndez, 2007; Nielsen et al., 2007; Vesely, 2007; Bernath and Roschewitz, 2008; Bullock, 2008; Chen and Jim, 2008; del Saz-Salazar and Rausell-Köster, 2008). However, the pursuit of economic value seems questionable given the nature of UGS. Unlike other environmental goods, public green space in city areas can act as a civic open space and 'social room' for the local community. Conventional economic treatment may lead to misinterpretation. In view of the conceptual flaws, new concepts and analytic approaches have been developed in rural forestry research (Blamey et al., 1995; Noël et al., 2000). Amongst UGS and forest researchers, the limitations of the techniques have largely gone unnoticed or, at least, have not appeared to be of sufficient concern for comment.

This article focuses on UGS and aims to show in what aspects the values elicited from stated-preference techniques are divorced from the essence of what constitutes this natural-cum-cultural concept. Scientific studies involving the use of stated-preference techniques in an urban or peri-urban context are selected for review. There is a focus on key practitioners who have multiple publications on the topic at issue and those who have more clearly shown the ways in which stated preferences are construed as environmental values.

The article begins by elaborating the social values of UGS. Selected studies are then reviewed to describe their theoretical basis and line of reasoning. Identifiable problems and implications are discussed at length. The importance of a structural change in valuation methodology is highlighted and alternatives suggested. 


\section{The social values of UGS}

UGS takes various forms, including public parks, sports and play areas, vegetated sitting-out areas, green corridors and urban woodlands. ${ }^{2}$ It provides a variety of benefits by enhancing the liveability of cities and contributes to a harmonious relationship between humans and nature.

Publicly accessible UGS plays a dual role by comprising greenery and open space. People appreciate natural coverage in city areas for its ecological, amenity, psychological and health benefits. Trees help regulate the microclimate, absorb air pollutants and abate noise. Greenery can also improve the aesthetic of otherwise drab neighbourhoods and raise psychological comfort. Open areas, on the other hand, provide places for outdoor sports activities, social interactions and community and cultural events.

Unlike other environmental entities, UGS has a salient socio-cultural role. Geographical experience nurtures affective attachment and loyalty to the places concerned. By enabling socialization and neighbourly contacts, properly managed open areas facilitate inhabitants' engagement in the community and carry people's memories, contributing to community and family ties (Burgess et al., 1988; Kuo, 2003). A sense of 'place' is developed through the enrichment of people's social life, sometimes irrespective of the area's quality.

UGS can also contribute to social justice (Baycan Levent and Nijkamp, 2005). Publicly accessible neighbourhood parks can foster social inclusion and interaction (Kweon et al., 1998; Taylor et al., 1998). This is particularly important for residents of compact inner-city areas, where minority and disadvantaged groups are found (e.g. new immigrants, ethnic minorities, the poor and the elderly). Such groups can find themselves restricted to overcrowded, unpleasant household living arrangements. Many of them cannot afford long-distance travel and have few free recreational alternatives. Small neighbourhood green spaces then provide a convenient place for socializing and exercise. Public parks make possible equal access to basic recreational opportunities and enable human encounters and participation in community life for those who would otherwise be socially isolated and ignored.

The perceived value of UGS may be oriented to rights and civic virtues in several dimensions, which indicate that its social significance goes beyond recreational benefits. Trees are perceived to have rights to exist, and this is particularly true for big old trees recognized as city landmarks. UGS may manifest as a cultural symbol. A special example is stone-wall trees in old and compact built-up areas (Jim, 1998). This unusual form of landscape involves spontaneous colonization by tall trees and other vegetation of old stone walls, walls that are old enough to be part of urban history and colonial legacy in some cases. The organic blending of key environmental and cultural assets has made them a precious natural-cum-cultural heritage. Publicly owned green space of this sort, physically integrated with a cultural asset, is likely to considerably enhance the attitude towards conservation as a sense of community recognition. Key civic parks may also act as a cultural metaphor and create local pride (Woolley, 2003).

An unintentional function of large public parks is the opportunity for people to participate in outdoor collective activities with a particular social or political theme (Cranz, 1982). As a physical manifestation of the political concept of the public sphere, urban open space may be seen as a political symbol linked to democratization (Ward Thompson, 2002). Examples include Speakers Corner in London's Hyde Park, and the Victoria Park and Chater Garden in Hong Kong where many political activities and demonstrations take place (Law, 2002). Lastly, the function of social inclusion helps realize social justice and the moral ideal of equality.

2 UGS takes many forms and is described in different terms (e.g. urban forests). Nevertheless, public parks are the most common and there is a basic similarity in the contributions that all public parks make. In this article I mainly focus on those green spaces that are publicly accessible. 
To study this multifaceted environmental entity, UGS researchers are accustomed to situate themselves in multiple knowledge frameworks, creating a pluralistic research tradition. The research frequently draws on various systems, including natural science, urban planning, economics, cultural studies, psychology, geography, architecture and sociology. Despite variations in research assumptions and contexts, distinctive conceptions of values are recognized and accommodated. The research atmosphere is sufficiently open to accommodate the use of different methodologies, including monetary valuation techniques.

\section{The perceived meanings of values and valuation}

This section reviews the valuation studies to show how the values are understood and handled as a monistic economic construct.

\section{Consumer values}

Many of these studies begin with an explicit endorsement of the neoclassical economic theory (Li and Cao, 2007; Nielsen et al., 2007; Bullock, 2008). UGS is then conceptualized in a hypothetical context as a consumer good that respondents express an intention to purchase to satisfy their wants. A use-oriented definition of value is adopted. For example, Tyrväinen (2001: 76) states that: 'In theory, the value of the green area depends on the amount and type of use and the availability of substitute areas', and that she believes CVM is theoretically capable of capturing the 'total value of urban forest benefits'. Similarly, Bullock (2008) employs choice experiments to isolate the values of individual attributes of UGS. His study is restricted to use benefits only, while he acknowledges that demand for green space is diverse and the aggregation of partial utility might not be realistic because alternative value dimensions exist. Issues of value diversity are avoided.

Chen and Jim (2008) obtain a low value estimate which they explain as being due to only capturing leisure value (i.e. direct use), not ecological and existence values. The implied assumption is that individuals are cognitively able to separate different types of values consciously and state them individually in a hypothetical context (e.g. CVM). This is not justified by the psychological literature (Gregory, 2000). Where non-use components are included by researchers they are subsumed within a utilitarian framework. Thus, Lockwood and Tracy (1995: 156) define the existence value of an urban recreational park as a kind of 'benefit' received by those who expect to derive satisfaction from knowing the site is preserved.

Park users are then seen as consumers. Del Saz-Salazar and Rausell-Köster (2008: 244) introduce economic welfare theory as they linked values to park use:

the individual who visits the park experiences an increase in his utility or well-being as a consequence of the different benefits that are obtained from using the park. This individual is therefore willing to pay an amount of money in order to secure this utility gain.

Likewise, Li and Cao (2007: 2443) are convinced that WTP elicited from CVM is meant to reflect 'consumer confirmation' of the value of a self-benefiting public commodity. This accords with the textbook definition that market value is determined by consumers' choices which depend on their subjective well-being and desires. Environmental values are understood as deriving from a one-to-one relationship between individual consumers and park components, involving 'a utility maximisation process' in which the utility function 'depends on income along with individual characteristics and the quality of objects to be valued' (Kwak et al., 2003: 2212). Wider social factors such as social norms do not count. 


\section{The market frame}

Markets are advocated as necessary for getting the right price structure to achieve the efficient allocation of resources via coordination of demand and supply. Environmental valuation is designed to address market failure and seek a correction in prices on the basis of revealing the 'true' value of resources. It is believed that the pre-existing environmental preferences, on which the 'true' value is based, can be adequately reflected by a hypothetical market which is properly constructed to resemble a real one. This reductionist perspective 'closes down' rather than 'opens up' the value landscape.

Green space researchers make every effort to fit their value assessments into the economic model. Choumert and Salanié (2008) believe that the perceived values of UGS are invariably economic, arising from resource scarcity, and a sound economic basis is necessary for cost-efficient resource allocation to satisfy the demand. From their perspective, environmental valuation is part of a cost-efficiency strategy to resemble the market place and address 'market failure'. This view is shared by environmental planners who believe that the 'problems in providing greenways and open spaces occur partly because of the absence or failures of markets such as inadequate knowledge and information about their benefits' (Lindsey and Knaap, 1999: 298).

Acceptance of the market failure model then is used to justify making valuation exercises as market-like as possible. Valuation formats such as dichotomous bidding and choice modelling are increasingly popular for their assumed ability to mimic real markets (Kwak et al., 2003; Treiman and Gartner, 2006; Li and Cao, 2007; Nielsen et al., 2007; Vesely, 2007; Bullock, 2008; Chen and Jim, 2008). The justification provided suggests a belief that environmental values are best articulated through markets by definition. To justify good use of the techniques, making economic sense is seen as the rule of thumb. As a rule, therefore, UGS has to be conceptually taken as a hypothetically tradable commodity that is put in a showcase (the questionnaire). The tendency to make value elicitation more economically sound is a pragmatic adjustment to comply with the concepts employed. The reality construction involved need not be authentic, for authenticity means the markets failing to work.

Nature may be valued only outside markets. Noël et al. (2000) have shown that many forest owners refused to sell their forests regardless of the offered amounts, as the forests are considered a historical-cultural metaphor representing the people's identity. To some respondents, the economists' approach is alien; that is, the idea of trading nearby natural areas where people develop a joyful childhood or family life for money or replacing them with a golf course (Burgess et al., 1998; Clark et al., 2000). To make environmental values more economic is likely to repeat the failure of markets to allow different types of values to be expressed, that is, non-economic ones.

Following the market choice perspective, a 'true' preference is assumed to exist. Many articles literally include the term 'true value' (Breffle et al., 1998; Pepper et al., 2005; Treiman and Gartner, 2006; Nielsen et al., 2007). For these practitioners, the purpose of using stated-preference techniques is to show what respondents already have in mind. This view influences both the choice of elicitation format and the interpretation of results. Bounded dichotomous choice is commonly employed to set a range for testing and capturing the 'true' value that individuals hold. Pepper et al. (2005) reckon that in their study of urban parks, protest bids came from respondents who did not make a 'true' valuation. They censor and distinguish them from genuine zeros by asking the respondents whether an annual one dollar levy is acceptable, where acceptance is taken to indicate the presence of a positive and 'true' value. There is a belief that the 'true' value is out there to be captured by refining survey procedures. This approach supports taking environmental assessment as a process of seeking objective truth, resembling a scientific exercise.

The technocratic view goes with a marginalization of symbolic values. Unstable, non-pre-existing preference is considered a source of error. In view of the great variation between individual stated WTPs, Lindsey and Knaap (1999: 311) conclude that the value 
estimates provided by CVM are not precise and are too 'subjective' to be a solid basis of policymaking. Price (2000) doubts the inclusion of passive use values as they contribute to slippery and symbolic responses putting the CVM into a failure. The conclusion turns out to be avoiding intrinsic dimensions to make the methodology viable.

To minimize subjective elements, specific survey designs or procedures have been employed to remove potential 'bias' and economic principles have been invoked to demarcate 'irrational' responses (Breffle et al., 1998; Tyrväinen and Väänänen, 1998). Embedding effects, for example, are observed as the WTP levels for urban forest prove insensitive to the size of the potential construction areas (Tyrväinen and Väänänen, 1998: 115). Yet the observation is defended as reasonable by the economic law of decreasing marginal utility. However, Daniel Kahneman, the Nobel prize-winning psychologist who famously raised the issue of an embedding effect, is reluctant to treat CVM responses as economic preferences but instead sees them as an expression of attitude. As he states, the observed inconsistency of stated WTP:

is an unavoidable consequence of basic cognitive and evaluative processes. It is not a result of defective procedures, and it will not be eliminated by improved survey methods (Kahneman et al., 1999: 221).

Based on a psychological technique (verbal protocol analysis), Schkade and Payne (1994) find that the respondents have no pre-existing and complete preference when responding to WTP questions. There is no stable preference order, or 'true' value, for environmental goods. The predisposition underlying the pursuit of a 'true' economic value relating to environmental change has then been found wanting in relationship to psychological findings.

\section{The treatment of protest responses}

The foregoing theoretical premises result in an arbitrary exclusion of protest responses (Spash, 2008a). As customary in CVM surveys, UGS researchers strive to reduce protest responses to a minimum (Tyrväinen and Väänänen, 1998; Bullock, 2008; del Saz-Salazar and Rausell-Köster, 2008). Bidding behaviours at variance with economic assumptions are classified as a bias. Bullock (2008) contends that an advantage of choice modelling is reducing the risk of strategic bias. Lockwood and Tracy (1995) worry that their estimates might suffer from underestimation due to the strategic responses resulting from the open-ended format. Tyrväinen and Väänänen (1998) also warn that the use of tax as a payment vehicle could encourage protests. Protest behaviours are seen as a framing problem to be resolved by better design and they would otherwise contaminate the results.

Defining anomalies as bias has justified ignoring or excluding protest behaviours. While it may be reasonable to remove truly strategic responses, the censorship treatment is often not grounded on a serious examination of the rationale for protest, its legitimacy and subjective consistency (Pepper et al., 2005; Jim and Chen, 2006; del Saz-Salazar and Rausell-Köster, 2008; Bowman et al., 2009). Protest responses are only briefly mentioned in a supplementary note at the end of Breffle et al.'s (1998) paper. Almost no word is given in Li and Cao (2007). Protest bids were even removed without an explanation in Lockwood and Tracy (1995) and Bowman et al. (2009). The removal was handled as a standard procedure. The reasons for and criteria of exclusion were assumed to be universally accepted, so that no detailed explanation was deemed necessary.

Motives are often mistakenly and inconsistently attributed to respondents and the classification of bids. Jim and Chen (2006: 92) erroneously classify protest response as deriving from respondents' poor economic status and non-use of UGS (zero bids based on these are normally defined as genuine zeros). All zero-bidding motives are again classified as a sort of protest in their later studies (Chen and Jim, 2008). Furthermore, 
follow-up treatments were no more than censoring and excluding for robust statistical modelling (Breffle et al., 1998; del Saz-Salazar and Rausell-Köster, 2008). Del SazSalazar and García Menéndez (2007) identified less than 1\% of their respondents who refused to bid as protesting for non-consequentialist motives, but did not explain why the same test was not applied to zero bidders as well, which account for $64 \%$ of the total sample. They fail to recognize that refusal to bid and zero bids may share similar motivational patterns, and therefore fail to detect the potentially large number of protest responses in their zero bidder samples (which would pose a challenge to the economic model adopted).

Most of the UGS studies fail to take the motives behind protest responses seriously. Reasons are offered, including objecting to the idea of valuing nature or having paid enough tax. Yet attempts to clarify why people protest are restricted to economists' usual explanation, namely, being irrational. Respondents are then deemed to protest when they are unable to, or refuse to, express their expected utility. Protest responses do not reflect their 'true valuation of the resource', but 'some concern about the survey design itself' (Pepper et al., 2005: 191). Concerns about the other aspects often go unexplained or understated. Results from any follow-up questions meant to ascertain bidding motivations occupy little space in the papers or are not reported at all (e.g. Kwak et al., 2003; Treiman and Gartner, 2006). Such questions are omitted in the questionnaire of Jim and Chen (2006), making their explanations of bidding motives purely personal speculation. Del Saz-Salazar and Rausell-Köster (2008) found a significant number (79\%) of zero bids in their valuation experiment. They define true zeros but pay little attention as to causes of protest zeros. Standard economic explanations are provided, i.e. the environmental change does not enter into the respondents' preference function, or they are unfamiliar with the task.

In contrast, Lo and Jim (2010b) find that protest bidders have a moderate positive preference for UGS, suggesting that contributions to nature might still fall within their preference function despite a failure to bid. A similar conclusion is reached by Vesely (2007), where $55 \%$ of those respondents who refused to pay the contingent bid accepted to contribute volunteer work for city tree conservation. On other environmental topics, Jorgensen and Syme (2000) and Meyerhoff and Liebe (2006) empirically show that protest behaviours can predict WTP level. Researchers cannot then justify identifying the determinants of positive WTP while arbitrarily censoring protest responses as if the two were independent (Spash, 2008a).

Attitudes can have a strong influence on WTP decisions (Kotchen and Reiling, 2000; Spash, 2000). A growing body of research has suggested that protest beliefs are related to non-consequentialist attitudes. Spash et al. (2009) affirm the role of ethical positions by showing that rights-based and consequentialist beliefs differ significantly in the influencing they have on individuals' choice of WTP categories and WTP levels. About $40 \%$ of their respondents who refused to pay in principle held a non-consequentialist position. Attitudes are one indication of alternative forms of value expression regarding the environment. According to Burgess et al. (1998) and Clark et al. (2000), protest responses are attributable to moral beliefs, sentimental attachment and cultural linkage to green areas. Holders of strong deontological positions tend to be hostile to the commodification of the environment and reject the principle of substitution. This might lead them to reject the offered bidding game and partially explain why people protest in CVM. Although rights-based respondents have in fact also been shown to be overrepresented in positive bid categories (Spash, 2006).

Exclusion of respondents is also likely to render estimation of non-use values problematic. Non-use values, such as existence value, may be closely related to rightsbased beliefs. Lockwood and Tracy (1995) seek a separate estimation of the non-use values of an urban park. But, because they exclude protest bids, the result is biased.

The standard practice of classifying non-economic motives as irrational and anomalous embodies the notion of value monism, i.e. only one value category counts (utilitarianism). Wider, multiple perspectives beyond the philosophical ambit of 
neoclassical economics are compromised. The expression of citizen's values is suppressed, leading to the failure to capture the entirety of social values.

\section{The misinterpretation of social values}

The reduction of social values to economic ones runs counter to the arguments for a valuation of the ignored contributions. Tyrväinen et al. (2007) call for more attention to the social and cultural dimensions of urban forest. In an earlier CVM study, Tyrväinen (2001:76) criticizes the narrow planning focus on financial appraisal and natural sciences, and advocates plural perspectives in measuring 'human values more comprehensively' and the 'type of values people attach to urban forests'. Disappointingly, the promise to widen value dimensions is dealt with by the traditional, monistic welfare-economic approach. Standard economic assumptions and exclusion procedures were applied in Tyrväinen and Väänänen (1998), making the promise mere rhetoric. If those 'human values' mean the social and cultural significance described by Burgess et al. (1988), the exclusion procedures may have effectively eliminated precisely what these researchers sought.

Del Saz-Salazar and Rausell-Köster (2008: 242) have also conveyed confusing messages. They claim to estimate the 'social benefits' arising from the use of Spanish urban parks, but, as quoted earlier, expect CVM to measure WTP for securing individual utility gain. Social values are defined as collective well-being equivalent to the sum of individual preferences - a point persistently criticized as unjustified (Sagoff, 1988; Spash, 2008a; 2008b). More confusing is that the 'aggregation' by del Saz-Salazar and Rausell-Köster (2008: 249) restates the intention to estimate social benefits, but then concedes that they were 'capturing mainly use values although the respondent may have other benefits in mind when responding to the valuation question'. Are the 'social benefits' subsumed under the banner of 'use values'? The meaning of 'other benefits' also remains mysterious. The writers have equated social benefits to instrumental values and appear reluctant to introduce non-economic explanations that would pose problems for preference aggregation. This view ignores a social role of UGS concerning social inclusion (justice) and community ties, which are hard to comprehend as personal and instrumental.

A convenient claim also appears in Jim and Chen (2006: 94): 'The estimate of willingness-to-pay emanates from the premises that social values should be based on individual values'. No distinction is made between social values and amenity and recreational benefits accrued to individuals. There is a categorical mistake in treating social values as derived from isolated individuals evaluating a limited set of private benefits, rather than a holistic evaluation of the contributions to the society at large.

The social roles of UGS become ill-defined under such paradoxical terminology as 'individual social value'. Choumert and Salanié (2008) contend that the nonexcludability of public green areas is a cause of abuse and the so-called "crowding externalities'. A remedial measure they suggest is to charge an entrance fee to eliminate free-riding. Although they note that this does not work for major parks with key social and historical significance, for others which 'are relatively small and often enclosed', such as public squares or gardens, excluding some 'consumers' (park users) may be feasible (Choumert and Salanié, 2008: 333). Small green space in inner-city areas can promote social inclusion and benefit the economically deprived. This function is likely to be eroded when market force is operative.

For example, some public parks in the inner-city areas of Hong Kong are persistently occupied by the South-Asian minority, unemployed individuals or those belonging to a lower social class (Lo and Jim, 2010a). These parks have a function with respect to social inclusion. Park congestion and chronic occupation by these people may be seen as a nuisance by other park users. Individualistic valuation may fail to capture this communal value, which does not stem from individual utility gains but a realization of social justice. 
Kleiber (2001) has shown that individuals are willing to pay to exclude park user groups that they dislike, such as these individuals. Moreover, there are reported cases in which the public's attitudes towards those public parks that are perceived to be 'hijacked' by private property management appear to be oriented to procedural justice (Cheng, 2009). Standard economic remedies would pose threats to these justice concerns and can hardly internalize them. Alternative measures, such as group techniques, are needed to support the elicitation of these alternative values.

\section{Pragmatism and pluralism}

There is a belief that where an economic method is applied, the value outputs must be economic and should be articulated in this manner. Some practitioners appear to be aware of the non-economic aspects but then keep them hidden. Nielsen et al. (2007) recognize the ethical basis of environmental preferences, but are blind to its theoretical inconsistency with the stated concepts of 'rational respondent behaviour' and 'neoclassical economic theory'. Chen and Jim (2010) explicitly recognize the role of ethical motivations, but none of the statistical predictors they employ are relevant. Although some optimistic practitioners believe that CVM is able to capture a wide range of benefits (e.g. Tyrväinen, 2001; Jim and Chen, 2006), some do acknowledge its problems and defend themselves by declaring that their focus is on a limited set of benefits explainable by individual utility function (e.g. Bullock, 2008). Making the monetary estimates useful to subsequent cost-benefit calculation is deemed more important than genuinely reflecting the real nature of UGS.

One reason is to fulfil economists' expectations. Bullock explains that economists select preference elicitation through choice modelling over ordinal ranking methods because it can mimic real market operations:

Unlike rankings or ratings, they are comfortable with the notion of choice. It is through the process of choice that goods are purchased or most policies decided upon. Economists can therefore respect a technique in which marginal attribute values can be derived from a large amount of choice data (Bullock, 2006: 243).

This seemingly makes the choice of valuation format something undertaken in order to earn economists' respect. There is an intention to keep everything within the economic boundary by limiting respondents' choice:

choice experiments avoid the need to request an overt expression of willingness to pay. Not only is it easier for a respondent to choose an alternative than to express willingness to pay, but the payment attribute is one or several attributes. This can 'mask the true purpose of the exercise' and make it more difficult for respondents to give a strategic response to influence the outcome of a study (ibid.).

Measuring the value of tree attributes in isolation thus makes life easier, despite the fact that individuals may not disaggregate the value as expected and may appeal to subtle reasons like personal memories inapprehensible to attribute measurement, something that Bullock (2008) admits.

The social quality of urban parks depends on the totality of their diverse uses and roles. People's use habits and attitudes towards UGS are determined by their sentimental attachment to a place and people, and their interaction with the social ambience. Economic conceptions of value are restricted to a monistic dimension. Multi-faceted roles are excessively constrained, reducing their integrity and meaning. To make neoclassical economists comfortable by choosing a 'respectful' valuation tool is literally moving away from the 'true purpose of the exercise', that is, to demonstrate the various contributions of UGS. 
This reflects a value pragmatism where valuation attempts are pragmatically motivated regardless of authenticity. Policymakers favour such a manageable assessment approach, which seemingly makes the associated value concepts reasonable and legitimate. What should count, then, depends on what the method can do. The meansend relationship is confused as valuation method is justified largely irrespective of the properties of the values to be captured. The monetary values estimated are merely those that neoclassical economists want.

These limitations are not new to neoclassical economists. A typical response is to qualify their approach and the findings by downplaying the importance of value pluralism. Students of UGS could not benefit from such a disclaimer, because to make one would contradict the literature about this public good, which is committed to pluralism. This variation in epistemological traditions has gone unnoticed or ignored.

Blaming economists for all the failures may sound unfair. UGS researchers, notably urban ecologists, appear to have weak understanding of the philosophical basis of value plurality, leading to an unreflective acceptance of economic techniques. This environmental entity is valued by a wider range of evaluative attitudes than prescribed by neoclassical economics. Some of its social or cultural values are of a deontological and intrinsic type. The value of an urban park recognized as part of a culture may be expressed in the form of civic virtue; it is elicited to the extent in which it is appropriately valued. To the contrary, traditional economics operates on a different philosophical basis, namely, consequentialism. A good is valuable to the extent to which its qualities meet hedonic standards. The UGS researchers fail to make such distinction, as specified by Anderson (1993).

For example, in Baycan Levent and Nijkamp's (2005: 71) taxonomy of UGS values, the contribution of social justice is put under the category of 'social interaction value' classified as an 'indirect use value', which is understood in an economic utilitarian framework. This classification brushes aside the conflict between the two distributive principles of equality and efficiency. Contrary to this view, economic rationality is likely to crowd out such civic virtues (Frey and Jegen, 2001). Neither is the efficiency-oriented conception a widely shared model of justice. There is a need to explore the philosophical orientations of environmental values more adequately to ensure conceptual consistency.

\section{Inclusion of non-economic motives}

Importing the monistic approach to capture plural values is self-contradictory. Valuation of UGS should begin with exploring the nature of value plurality and then adopt a corresponding elicitation method. To design alternative valuation methods, issues about social sustainability and justice, in particular, have to be clarified. Conflict may exist between the different aspects of values. Environmental valuation should no longer merely serve value expression, but also accommodation of varied value systems and traditions.

More inclusive research strategies and procedures have been tested recognizing noneconomic factors and/or including deliberative elements in value assessment. Success has been variable, though, with some weaknesses apparent. Vesely (2007) notes the conceptual error associated with arbitrarily excluding protest bids and so keeps them as true zeros in the statistical model. ${ }^{3}$ To avoid the problem with intended monetary contributions, the willingness to vote of those who refused to pay was explored by asking

3 These protest bids were treated as zeros, based on Jorgensen and Syme's (2000) reasonable conclusion that these responses should not be censored. Yet coding protest as zero is no less problematic. A fairer treatment is, as Vesely (2007) did, to provide a separate calculation of WTP with and without these bids, plus an analysis of protest characteristics (although this part could have been strengthened). 
if they would do volunteer work for tree conservation. Motivations to take care of city trees were assessed and used to predict WTP. Strangely, their model combines rightsbased motives with utility-based tree benefits, which appears to be incompatible with the motives of existence rights. Gelso and Peterson (2005) propose that the recreational demand function is a function of a duty-based ethical attitude. The relationship between visitation of urban parks and ethical attitudes is demonstrated. Like Vesely (2007), they measure ethical attitude by a single, dichotomous question, which seems to be simplistic. Gelso and Peterson (2005) spend several pages explaining issues of ethical attitude and neoclassical value theory. Unfortunately, they do not show whether the former would influence WTP if it were measured, leaving their arguments unproved.

Bernath and Roschewitz (2008) explain the WTP for Swiss urban forests based on an established psychological theory. More attention is paid to protest response and attitudinal factors. They conclude that respondents' attitude and subjective norms could improve understanding of protest response but not bid levels. In view of the finding that WTP levels are a function of protest beliefs (Meyerhoff and Liebe, 2006), the relationship between attitude, protest response and WTP remains unclear and requires more research (Spash et al., 2009).

\section{A more radical alternative?}

Deliberative Monetary Valuation (DMV) has been emerging as a discourse-based valuation approach for eliciting multiple values in group settings, as a response to the persistent critiques of stated-preference techniques (Niemeyer and Spash, 2001; Howarth and Wilson, 2006; Spash, 2007). DMV is drawn from the theory of deliberative democracy. Environmental valuation takes place in deliberative institutions, such as citizens' juries and deliberative polls. By merging economic and political processes, these institutions create a social learning experience and a social space from which values for a particular environmental good are debated and determined. Information sharing and critical reflection are encouraged to allow preference transformation and reconstruction.

Individuals from different walks of life are recruited as deliberators to conduct one or several sessions of small-group discussion on a particular topic. Information is supplied by researchers and deliberators and exchanged with inputs from experts. Peer evaluation takes place following a principled set of rules about norms of communication. Deliberators interact with each other and mutually adjust their positions as they elaborate and defend their values and claims. Either an individual or a social WTP can be determined as an output. DMV is accessible to ethical and collective-social issues and different value categories. Still, concerns have been raised as to issues such as demographic representation and stability of response (Powe, 2005), WTP question format (Aldred, 2005) and theoretical validity (Vatn, 2009).

The present author is not aware of any published empirical applications to urban forestry or open spaces. Nevertheless, the method has been applied to other topics. James and Blamey (2005) conducted a citizens' jury on national park management, where participants were asked to determine society WTP for a specified conservation programme. The deliberation supported formulation of a WTP decision along certain democratic rules. Determining societal WTP through consensus-seeking and voting activities helped facilitate a citizen frame of reference. The citizen role at work has been confirmed by a post-deliberation statement prepared by the participants in agreement: 'we are a representative jury in the community' (James and Blamey, 2005: 234). The authors concluded that DMV could promote elicitation of societal preferences explainable in terms of social welfare functions.

DMV offers better communication opportunities among respondents. Dietz et al. (2009) employed a procedure of anonymous tabling of reasons. Each participant wrote down a list of reasons in relation to global warming and proposed one reason at a time. 
The proposed reasons were recorded and posted around the meeting room visible to all. The facilitator then asked for verbal comments on the listed reasons and prompted discussion. The process was repeated until all the reasons were covered. This procedure enabled orderly argumentation over all concerns raised, and free articulation of reasons and their revision. It placed little restriction on types of reason and forms of expression, making room for the putting forward of public reasons. Dietz et al. (2009) found that, statistically, the respondents' WTP was more significantly affected by their political orientations than those not involved in a group deliberation. The deliberation prompted political considerations couched in terms of public values, rather than the individual considerations that dominated responses to standard CVM surveys.

\section{Conclusion}

This article is not simply a critique of stated-preference techniques. A more important message is the need for value-articulating methodologies that are primarily driven by the notion of value pluralism. The current practice is method-driven, producing a distorted picture of the values associated with UGS. Declaring a narrow focus fails to take seriously the critiques. This inevitably creates a problem in unduly pulling the study of UGS away from the pluralistic tradition. There is thus confusion in the priority of means and ends. UGS is about plural values rather than economic values.

Practitioners appear to be appealing to value pragmatism. This has led researchers to attempt to fit their diverse value observations into an orthodox economic framework in order to meet the requirements of CBA and engage in a mainstream economic discourse about prices. Being pragmatic, however, in reality means displacing valuable green space from city areas. To play the economic 'game', UGS has to be construed and treated as a commodity.

The primary reason to play this game is to reflect the multiple values green space research has revealed, but which are not present in the market place. The definition and procedures then have an ambivalent relation to their aims. Some of the practitioners profess to estimate social values but subscribe to a utility maximization model. Environmental values are narrowly defined as individualistic and instrumental, leading to the dominance of the private and economic over the public and social. Understanding the philosophy and psychology of values would be the first step to addressing value pluralism, but only if undertaken in an open-minded fashion rather than with the aim of fitting all concepts into a narrow economic frame.

Alternatives are needed. As an emerging research approach, DMV may allow money values to be elicited on a reflective, social-constructive basis. The values can be rationalized through open discursive processes with the capacity for informing and transforming preferences. Openly accessible UGS is a public asset playing multi-faceted roles. After recognizing something as a plural social construct, why then try to define it as falling under a monistic economic value system derived from pricing consumer goods? Leaving the standard economic assumptions unquestioned, urban researchers could only explain the world in terms economists employ, not in terms of what they really observe and really want to explain.

Alex Y. Lo (alex.lo@anu.edu.au), Griffith School of Environment, Griffith University, Gold Coast Campus, Parklands Drive, Southport, Queensland 4222, Australia.

\section{References}

Aldred, J. (2005) Consumer valuation and citizen deliberation: towards a comparison. In M. Getzner, C.L. Spash and S. Stagl (eds.), Alternatives for environmental valuation, Routledge, London.
Anderson, E. (1993) Value in ethics and economics. Harvard University Press, Cambridge, MA.

Baycan Levent, T. and P. Nijkamp (2005)

Evaluation of urban green spaces. In D. 
Miller and D. Patassini (eds.), Beyond benefit cost analysis: accounting for non-market values in planning evaluation, Ashgate, Aldershot.

Bernath, K. and A. Roschewitz (2008) Recreational benefits of urban forests: explaining visitors' willingness to pay in the context of the theory of planned behavior. Journal of Environmental Management 89, 155-66.

Blamey, R.K., M. Common and J. Quiggin (1995) Respondents to contingent valuation surveys: consumers or citizens? Australian Journal of Agricultural Economics 39, 263-88.

Bowman, T., J. Thompson and J. Colletti (2009) Valuation of open space and conservation features in residential subdivisions. Journal of Environmental Management 90, 321-30.

Breffle, W.S., E.R. Morey and T.S. Lodder (1998) Using contingent valuation to estimate a neighbourhood's willingness to pay to preserve undeveloped urban land. Urban Studies 35, 715-27.

Bullock, C.H. (2006) Using choice experiments to value urban greenspace. In D.W. Pearce (ed.), Environmental valuation in developed countries, Edward Elgar, Cheltenham and Northampton.

Bullock, C.H. (2008) Valuing urban green space: hypothetical alternatives and the status quo. Journal of Environmental Planning and Management 51, 15-35.

Burgess, J., C.M. Harrison and M. Limb (1988) People, parks and the urban green: a study of popular meanings and values for open spaces in the city. Urban Studies 25, 455-73.

Burgess, J., J. Clark and C.M. Harrison (1998) Respondents' evaluations of a CV survey: a case study based on an economic valuation of the Wildlife Enhancement Scheme, Pevensey Levels in East Sussex. Area 30, 19-27.

Chen, W.Y. and C.Y. Jim (2008) Cost-benefit analysis of the leisure value of urban greening in the new Chinese city of Zhuhai. Cities 25, 298-309.

Chen, W.Y. and C.Y. Jim (2010) Resident motivations and willingness-to-pay for urban biodiversity conservation in Guangzhou (China). Environmental Management 45, 1052-64.

Cheng, L.H. (2009) Shěn shì gōng gong kōng jiān: màn wú fāng xiąng de zhuī xún?
[Assessing public spaces - an unfocused endeavour?] Paper presented at the Annual MCS Symposium, Hong Kong Cultural Center, Lingnan University, Hong Kong, 7 February.

Choumert, J. and J. Salanié (2008) Provision of urban green spaces: some insights from economics. Landscape Research 33, 331-45.

Clark, J., J. Burgess and C.M. Harrison (2000) 'I struggled with this money business': respondents' perspectives on contingent valuation. Ecological Economics 33, 45-62.

Cranz, G. (1982) The politics of park design: a history of urban parks in America. MIT Press, Cambridge, MA.

del Saz-Salazar, S. and L. García Menéndez (2007) Estimating the non-market benefits of an urban park: does proximity matter? Land Use Policy 24, 296-305.

del Saz-Salazar, S. and P. Rausell-Köster (2008) A double-hurdle model of urban green areas valuation: dealing with zero responses. Landscape and Urban Planning 84, 241-51.

Dietz, T., P.C. Stern and A. Dan (2009) How deliberation affects stated willingness to pay for mitigation of carbon dioxide emissions: an experiment. Land Economics 85, 329-47.

Frey, B.S. and R. Jegen (2001) Motivation crowding theory. Journal of Economic Surveys 15, 589-611.

Gelso, B.R. and J.M. Peterson (2005)

The influence of ethical attitudes on the demand for environmental recreation: incorporating lexicographic preferences. Ecological Economics 53, $35-45$.

Gregory, R. (2000) Valuing environmental policy options: a case study comparison of multiattribute and contingent valuation survey methods. Land Economics 76, 151-73.

Howarth, R.B. and M.A. Wilson (2006) A theoretical approach to deliberative valuation: aggregation by mutual consent. Land Economics 82, 1-16.

James, R.F. and R.K. Blamey (2005) Deliberation and economic valuation: national park management. In M. Getzner, C.L. Spash and S. Stagl (eds.), Alternatives for environmental valuation, Routledge, London, New York.

Jim, C.Y. (1998) Old stone walls as an ecological habitat for urban trees in Hong 
Kong. Landscape and Urban Planning 42, 29-43.

Jim, C.Y. and W.Y. Chen (2006)

Recreation-amenity use and contingent valuation of urban greenspaces in Guangzhou, China. Landscape and Urban Planning 75, 81-96.

Jorgensen, B.S. and G.J. Syme (2000) Protest responses and willingness to pay: attitude toward paying for stormwater pollution abatement. Ecological Economics 33, 251-65.

Kahneman, D., I. Ritov and D. Schkade (1999) Economic preferences or attitude expressions?: an analysis of dollar responses to public issues. Journal of Risk and Uncertainty 19, 203-35.

Kleiber, O. (2001) Valuation of recreational benefits and visitor conflicts in an urban forest. Paper presented at the Fifth International Conference of the International Society for Ecological Economics (ISEE) Russian Chapter (Russian Society for Ecological Economics), 'Ecological Economic Management and Planning in Regional and Urban Systems', Institute of Control Sciences, Russian Academy of Sciences, Moscow, 26-29 September.

Kotchen, M.J. and S.D. Reiling (2000) Environmental attitudes, motivations, and contingent valuation of nonuse values: a case study involving endangered species. Ecological Economics 32, 93-107.

Kuo, F.E. (2003) The role of arboriculture in a healthy social ecology. Journal of Arboriculture 29, 148-55.

Kwak, S.-J., S.-H. Yoo and S.-Y. Han (2003) Estimating the public's value for urban forest in the Seoul Metropolitan Area of Korea: a contingent valuation study. Urban Studies 40, 2207-21.

Kweon, B.-S., W.C. Sullivan and A.R. Wiley (1998) Green common spaces and the social integration of inner-city older adults. Environment and Behavior 30, 832-58.

Law, L. (2002) Defying disappearance: cosmopolitan public spaces in Hong Kong. Urban Studies 39, 1625-45.

Li, Y. and Y.K. Cao (2007) Analysis on the factors influencing the residents' willingness to pay to the urban forest ecosystem services - taking Harbin for example. Paper presented at the $14^{\text {th }}$ International Conference on Management Science and Engineering, Harbin, China, 20-22 August.
Lindsey, G. and G. Knaap (1999) Willingness to pay for urban greenway projects. Journal of the American Planning Association 65, 297-313.

Lo, A.Y. and C.Y. Jim (2010a) Differential community effects on perception and use of urban greenspaces. Cities 27, 430-42.

Lo, A.Y. and C.Y. Jim (2010b) Willingness of residents to pay and motives for conservation of urban green spaces in the compact city of Hong Kong. Urban Forestry \& Urban Greening 9, 113-20.

Lockwood, M. and K. Tracy (1995) Nonmarket economic valuation of an urban recreation park. Journal of Leisure Research 27, 155-67.

Meyerhoff, J. and U. Liebe (2006) Protest beliefs in contingent valuation: explaining their motivation. Ecological Economics 57, 583-94.

Nielsen, A.B., S.B. Olsen and T. Lundhede (2007) An economic valuation of the recreational benefits associated with nature-based forest management practices. Landscape and Urban Planning 80, 63-71.

Niemeyer, S. and C. Spash (2001) Environmental valuation analysis, public deliberation, and their pragmatic syntheses: a critical appraisal. Environment and Planning C: Government and Policy 19, 567-85.

Noël, J.-F., M. O'Connor and J.K.S. Tsang (2000) The Bouchereau woodland and the transmission of socio-ecological economic value. Ecological Economics 34, 247-66.

O'Neill, J. (2007) Markets, deliberation and environment. Routledge, London.

Pepper, C., L. McCann and M. Burton (2005) Valuation study of urban bushland at Hartfield Park, Forrestfield, Western Australia. Ecological Management and Restoration 6, 190-6.

Powe, N.A. (2005) Redesigning environmental valuation: mixing methods within stated preference techniques. Edward Elgar, Cheltenham.

Price, C. (2000) Valuation of unpriced products: contingent valuation, cost-benefit analysis and participatory democracy. Land Use Policy 17, 187-96.

Sagoff, M. (1988) The economy of the earth: philosophy, law, and the environment. Cambridge University Press, Cambridge.

Schkade, D.A. and J.W. Payne (1994) How people respond to contingent valuation questions: a verbal protocol analysis of 
willingness to pay for an environmental regulation. Journal of Environmental Economics and Management 26, 88-109.

Spash, C.L. (2000) Ecosystems, contingent valuation and ethics: the case of wetlands re-creation. Ecological Economics 34, 195-215.

Spash, C.L. (2006) Non-economic motivation for contingent values: rights and attitudinal beliefs in the willingness to pay for environmental improvements. Land Economics 82, 602-22.

Spash, C.L. (2007) Deliberative monetary valuation (DMV): issues in combining economic and political processes to value environmental change. Ecological Economics 63, 690-9.

Spash, C.L. (2008a) Contingent valuation design and data treatment: if you can't shoot the messenger, change the message. Environment and Planning C: Government and Policy 26, 34-53.

Spash, C.L. (2008b) How much is that ecosystem in the window? The one with the bio-diverse trail. Environmental Values 17, 259-84.

Spash, C.L. (2009) Editorial: The new environmental pragmatists, pluralism and sustainability. Environmental Values 18, 253-6.

Spash, C.L., K. Urama, R. Burton, W. Kenyon, P. Shannon and G. Hill (2009) Motives behind willingness to pay for improving biodiversity in a water ecosystem: economics, ethics and social psychology. Ecological Economics 68, 955-64.

Taylor, A.F., A. Wiley, F.E. Kuo and W.C. Sullivan (1998) Growing up in the inner city: green spaces as places to grow. Environment and Behavior 30, 3-27.

Treiman, T. and J. Gartner (2006) Are residents willing to pay for their community forests? results of a contingent valuation survey in Missouri, USA. Urban Studies 43, 1537-48.

Tyrväinen, L. (2001) Economic valuation of urban forest benefits in Finland. Journal of Environmental Management 62, 75-92.

Tyrväinen, L., K. Mäkinen and J. Schipperijn (2007) Tools for mapping social values of urban woodlands and other green areas. Landscape and Urban Planning 79, 5-19.

Tyrväinen, L. and H. Väänänen (1998) The economic value of urban forest amenities: an application of the contingent valuation method. Landscape and Urban Planning $43,105-18$.

Vatn, A. (2009) An institutional analysis of methods for environmental appraisal. Ecological Economics 68, 2207-15.

Vesely, E.-T. (2007) Green for green: the perceived value of a quantitative change in the urban tree estate of New Zealand. Ecological Economics 63, 605-15.

Ward Thompson, C. (2002) Urban open spaces in the 21 st century. Landscape and Urban Planning 60, 59-72.

Woolley, H. (2003) Urban Open Spaces. Spon Press, London and New York.

\section{Résumé}

L'évaluation monétaire de l'espace vert urbain à l'aide de modèles basés sur les préférences déclarées a pris de l'importance chez les auteurs pragmatiques de la recherche urbaine, mais le fait qu'elle affaiblit le potentiel du pluralisme des valeurs est passé inaperçu. Les concepts de valeur se mélangent. Les valeurs publiques sociales ont été traitées comme des valeurs privées économiques. La capacité de refléter les multiples valeurs et rôles sociaux de la nature urbaine a donc été réduite. La pratique, mue par la méthode, ne rejoint pas l'objectif exprimé de représenter intégralement cet espace. Bien que les différentes facettes de son rôle soient généralement reconnues, il se crée une compréhension inadéquate de la philosophie et de la psychologie des valeurs associées à l'espace vert urbain. C'est ainsi que les techniques économiques sont acceptées sans discernement. Il faut envisager d'autres études pour clarifier les aspects liés à la manifestation et au fondement théorique du pluralisme des valeurs. Des approches délibératives pourraient constituer une méthode d'évaluation complémentaire ou alternative. 